\title{
A qualitative study of patients' experiences and acceptance of computerised cognitive behavioural therapy in primary care, Scotland
}

\author{
Eliane Du ${ }^{1 \star}$, Ethel Quayle ${ }^{1}$ and Hamish Macleod ${ }^{2}$ \\ ${ }^{1}$ Clinical and Health Psychology, School of Health in Social Science, University of Edinburgh, Edinburgh, UK and ${ }^{2}$ The Moray \\ House School of Education and Sport, Institute for Education, Community and Society, University of Edinburgh, Edinburgh, UK \\ *Corresponding author. Email: eliane.du@ed.ac.uk; dueliane@gmail.com
}

(Received 20 October 2020; revised 3 July 2021; accepted 5 July 2021)

\begin{abstract}
Computerised cognitive behavioural therapy (CCBT) has been made available within the National Health Service (NHS) across Scotland as an alternative treatment for mild to moderate anxiety and depression. However, the provision of CCBT services is still limited in the NHS, possibly affecting delivery of this computer-aided therapy to patients and inhibiting acceptance and uptake of this intervention. This paper reports on the qualitative exploration of patients' experiences and acceptance of one CCBT programme delivering computer-assisted therapy (Beating the Blues: BTB), examining particularly the point of referral, access to treatment, and support. Thematic analysis was conducted on semistructured face-to-face and email interviews with 33 patients at different NHS organisations across Scotland. Data analysis generated six key themes which illustrated patients' experiences relating to referral and access to the treatment, and the challenges they faced: (1) information dissemination; (2) expectations and the impact of waiting for BTB; (3) impact of locations on experience of BTB; (4) preference for home access; (5) desire for better human support; and (6) desire for additional application support features. The findings highlighted that better methods of implementing and delivering such CCBT services together with the design of the technological interventions are vital to the success of these services.
\end{abstract}

\section{Key learning aims}

(1) To understand the service models and methods of implementing and delivering one CCBT programme (BTB) in routine care;

(2) To learn about user experiences of accessing and using BTB; and

(3) To learn about the implications and factors that might have influenced uptake and understand the implications.

Keywords: access to CCBT; Beating the Blues; computerised cognitive behavioural therapy; library/clinic setting; patient experience; service implementation

\section{Introduction}

Depression and anxiety disorders are major contributors to the global burden of human disease (NICE, 2014; Shah et al., 2021; Vos et al., 2012; WHO, 2012). In the United Kingdom (UK), one in 10 people are diagnosed with anxiety or depression (Mental Health UK, 2021) and about $12 \%$ of the population take anti-depressants daily (Smith et al., 2020; SPICe, 2014). Medication is the 
most common treatment provided by general practitioners (GPs) (Kivi et al., 2015) as it is relatively cheap, and easy to dispense (Andrews et al., 2018). Psychotherapy or face-to-face cognitive behavioural therapy (CBT) is another effective treatment for depression, but demand for trained therapists greatly outstrips supply (Santucci et al., 2014), leading to lengthy waiting lists that, in Scotland, result in delays of between 12 and 22 months to see a therapist (Morkis, 2018). Thus, many patients remain untreated and their symptoms can become chronic or more severe over time, potentially leading to poorer treatment outcomes (Kessler et al., 2003; Kraus et al., 2019; Wittchen et al., 2011). To address these challenges, a range of CBT self-help materials have been developed and deployed via technology-based interventions, such as internet-based self-help or computerised CBT (CCBT) that can be offered as alternatives to face-to-face therapy (Collins et al., 2018; Kaltenthaler and Cavanagh, 2010).

CCBT uses multimedia formats and interactive features (Davies et al., 2014) that can be delivered via educational software packages, web platforms, smartphones, or handheld device applications (Bakker and Rickard, 2019; Richards et al., 2014; Spurgeon and Wright, 2010). Some of the advantages that CCBT can bring include: increased access to psychological treatment (24/7 from different locations), ability to reach wider audiences, cost efficiency, shorter waiting times compared with face-to-face therapy, privacy and anonymity, and less demand on clinician time (Barak and Grohol, 2011; Du et al., 2013; Folker et al., 2018). However, CCBT also has its disadvantages: it is not for everyone, it can be impersonal, and it lacks human and therapeutic contact (Taiminen et al., 2019; Wagner et al., 2014). It is worth noting that these drawbacks will vary depending on the nature and set-up of different CCBT programmes.

Evidence from systematic reviews and meta-analyses suggests that CCBT is an effective treatment for anxiety and depression and can be delivered with or without therapist guidance (e.g. self-guided or self-administered CCBT) (Andrews et al., 2018; Karyotaki et al., 2017; Olthuis et al., 2015; Păsărelu et al., 2017). The self-guided option allows physicians (e.g. GPs) not only to provide easy access to psychological treatments to many patients, but also to reduce costs of such treatments (Karyotaki et al., 2017). However, drop-out rates can be high for solely self-administered CCBT (Richards and Richardson, 2012), as some patients may prefer to have forms of support or human contact to aid motivation (Bennett et al., 2008). Guided CCBT (i.e. with support from a clinician or other person) has been shown to be more effective and has higher acceptance and treatment satisfaction ratings in studies than unguided CCBT (Wright et al., 2019). These higher ratings have also been found most often in studies that were conducted in community settings (e.g. school, library and/or samples recruited from advertisements, random volunteers, and other sources) rather than in primary care (e.g. GP clinics, hospitals) settings (Low et al., 2008; Wells et al., 2018). Furthermore, the use and uptake of CCBT to date is still low, which remains a challenge and a cause for concern (Clarke et al., 2015; Gilbody et al., 2015; Richards and Richardson, 2012; So et al., 2013; Wright et al., 2019). As noted in a review by Apolinario-Hagen (2019), the reasons for this are often not directly reported.

Nevertheless, due to the supporting evidence base, the National Institute for Health and Care Excellence (NICE, 2006; NICE, 2009a) and the Scottish Intercollegiate Guidelines Network (SIGN, 2010) have recommended that a psychological intervention or low-intensity (LI) treatments (e.g. CCBT, bibliotherapy, self-help guides) be used within the stepped-care model, as first-line treatment in National Health Service (NHS) primary care. The aim of this model is to improve access and increase effective mental health service delivery, starting with the least intensive and escalating to more intensive approaches (e.g. face-to-face therapy, specialist services) if necessary (NICE, 2009b). Self-guided CCBT programmes for mild to moderate anxiety and depression management, such as Beating the Blues (BTB) and MoodGYM, have previously been endorsed by NICE (NICE, 2009a). These programmes have been assessed during the past two decades for their clinical and cost effectiveness (Gilbody et al., 2015; 
McCrone et al., 2004; Proudfoot, 2004; Proudfoot et al., 2003). Moreover, randomised control trials (RCTs) and review studies have consistently supported BTB as a promising alternative option to traditional therapy (Health Quality Ontario, 2019). BTB has also been used in studies using different settings and populations and has yielded encouraging results (Beattie et al., 2009; Bennett et al., 2008; Gega et al., 2012; Gega et al., 2013; McMurchie et al., 2013; Mitchell, 2009; Mitchell and Dunn, 2007; Mitchell and Gordon, 2007; Nelson et al., 2014). In recent years, BTB has also been offered to NHS patients in England and Scotland, the latter being where this study's data were collected.

Although the use of CCBT in NHS primary care, in particular the BTB programme, is supported by the Scottish Government, a previous nationwide survey conducted by Kenicer et al. (2012) revealed that there is no national policy on how patients should access CCBT. In addition, the decisions about its use, often made at a local level, can differ across the 14 regional health boards in Scotland. The authors emphasised that NHS information technology (IT) infrastructure and policies may not yet be ready to fully support CCBT implementation and delivery, as access to CCBT at NHS sites is still limited due to lack of equipment and resources. These limitations could have an adverse impact on the use of CCBT, as methods of delivery can contribute to the effectiveness of treatment (Wright et al., 2019).

Studies to date have also reported ongoing challenges and mixed outcomes of CCBT implementation and delivery in routine care (Andersson et al., 2019). For instance, Folker et al. (2018) explored the differences and similarities between CCBT services across five different countries (Sweden, Norway, Denmark, The Netherlands and Scotland) and raised concerns about integrating CCBT into routine care systems, patient recruitment (e.g. model of referral), and the long-term sustainability of service. Other researchers also identified barriers and facilitators (e.g. engagement, support, limited resources, access to information) to CCBT implementation (Hadjistavropoulos et al., 2017), and challenges in practice (e.g. negative attitudes among stakeholders, GP awareness, availability of services) (Andersson et al., 2019; Breedvelt et al., 2019; Meisel et al., 2018; Lal, 2019). Thew's commentary (in his 2020 paper which refers to guided CCBT: Thew, 2020) noted that commonly held beliefs of practitioners might undermine confidence and motivation in providing treatment in this format. Such beliefs include concerns that there is a limited evidence base for online delivery and that it will not be as effective as face-to-face delivery, that therapeutic alliance may be less strong, and that such interventions are not suitable for more severe problems. Such beliefs, particularly in relation to the therapeutic alliance, are however challenged by qualitative research from Perera-Delcourt and Sharkey (2019) (also referring to guided CCBT), which concluded that their sample of patients did report benefit from the intervention and the accompanying online relationship, and noted that the immediacy of the availability was of value to them. The meta-analysis by Wells et al. (2018) also indicated that the effects of CCBT were strongly influenced by clinician support (or that of another helping person) and that the mode of delivery of that support did influence outcome.

As knowledge about effective CCBT implementation in primary care is still under-developed, it is difficult to judge which strategy or service model should be adopted, and how to disseminate CCBT (Folker et al., 2018). However, as noted by Thew (2020), CCBT approaches are already widely in use in routine care settings and as they have the potential to both deliver treatment effectively and to improve availability and access, their use is likely to increase in future years. More research therefore should focus on implementation strategies and ways of enhancing CCBT effectiveness, and computer and human integration elements to this therapy in healthcare settings (Wells et al., 2018). There is need for greater understanding of patient experience of CCBT (Rost et al., 2017), of related CCBT services, and of similarities and differences in the support offered (Gellatly et al., 2018). An in-depth qualitative exploration of barriers to access and user satisfaction is also warranted (Stefanopoulou et al., 2019). 
Despite growing evidence suggesting that guided CCBT seems to be more effective than unguided CCBT, the latter option has continued to be provided to patients across NHS Scotland since 2012 to save costs and cut long waiting lists for face-to-face therapy (Du et al., 2013). However, there are high drop-out and low compliance rates, reasons for which remain unclear. In light of CCBT researchers' suggestions that future research address some of the continuing barriers to implementation and delivery of this computer-aided therapy, this study was conducted to examine patients' experience and acceptance of CCBT. It aims to contribute to the existing literature and shed light on some of the reasons for the lack-lustre drop-out and compliance rates, poor engagement, and the challenges to improving them. This paper reports on the qualitative exploration of patients' experience and acceptance of one specific CCBT programme (BTB) delivered by the NHS across Scotland, especially addressing the point of referral, access to treatment, and support.

\section{Method}

These qualitative data were part of a larger mixed methods study, which was conducted to examine factors that might have influenced CCBT use and the whole user experience and usability. Thematic analysis (TA) (Braun and Clarke, 2013) was used to analyse face-to-face and email interviews. TA is a widely used method in qualitative research (Braun and Clarke, 2006), and in evaluation research for CCBT and other health interventions and technologies (Brown and Stockman, 2013; Cooney et al., 2018; Gega et al., 2013; Gega et al., 2012; Morrison et al., 2009; Perera-Delcourt and Sharkey, 2019). Besides face-to-face interviews, interviewing by email has also become widely used as a methodological and viable tool for data collection in health-related qualitative studies (Murray and Sixsmith, 2002). In addition to saving on costs and time (e.g. travelling, data transcribing), email interviewing enables researchers to access many potential individuals who might be hard to reach and, importantly, it allows interviewees time to think, reflect, and respond to the questions (Hawkins, 2018; James, 2016; Meho, 2006).

In this study, a semi-structured interview was used with the following guiding questions (the exact use of which depended on the patient's responses to earlier questions, especially in email interviews). This interview was developed by the first author with input from co-authors. It was guided by research on patients' experiences (Beattie et al., 2009; Bennett et al., 2008) to gain as much knowledge as possible and a better understanding of patients' perspectives and their satisfaction and acceptance of CCBT services. The overall aim was to gather user experience of CCBT in the wider context of its use. The list of interview questions was as follows:

(1) How did you find out about BTB?

(2) Were you given any information about BTB treatment before your first appointment with BTB?

(3) How long did you have to wait to get your first appointment with BTB? Was the waiting time acceptable?

(4) How did you feel when doing BTB at a library/NHS clinic/home?

(5) Did you have enough time to complete the session?

(6) How easy is it for you to ask for help if you have any questions about the sessions/ programme or if you need to talk to someone?

(7) If you were given an option to do BTB at another place (e.g. home), would you choose that? Why?

(8) Did you need any support while doing BTB or a review/follow-up during or at the end of the programme? Why? 


\section{Intervention}

Beating the Blues (BTB) (Proudfoot et al., 2003), a self-administered CCBT package, has been recommended for use in UK NHS trusts (Christensen et al., 2014). It has also been rolled out to NHS primary care across Scotland as one of its low intensity treatments and in self-guided format for patients with mild to moderate anxiety and depression ( $\mathrm{Du}$ et al., 2013; Folker et al., 2018; NHS Lothian, 2019; The Scottish Government, 2017). The BTB programme consists of eight weekly sessions, each of which takes approximately 50 minutes to complete. Homework assignments need to be completed in between sessions. It is also important to note that this study was carried out on the original BTB UK version. The NHS has now updated it to the US version. Although the UK version has a different interface and functionality (e.g. not linear, less interactive), the programme's concept is similar to the US version: five video case studies with the same storylines (but played by different actors), eight weekly sessions which last about 50 minutes each and also contain homework. Note, however, that the updated BTB version does not change the implementation, service delivery and the support factors which pertained to the previous version.

\section{Access to CCBT or BTB treatment}

As mentioned earlier, access to CCBT such as BTB, and its use and support were dependent on each local health board's resources and funding (as the cost of a licence can be more expensive for home users of the online programme version). It is also important to note that the time this qualitative data collection and analysis took place (between 2012 and 2015 as part of a larger mixed method study to examine the use and usability of CCBT programmes) some clinics and libraries that the patients attended had either a stand-alone or an online BTB version. However, due to limited available resources (e.g. computers, rooms) to accommodate BTB appointments, patients therefore would have to wait for available slots. Moreover, in the case of libraries, as the computers were also for public use and not specifically dedicated to BTB patients, they would need to book an appointment. Hence, CCBT delivery and its referral approaches varied across Scotland. As stated by Du et al. (2013), in some areas of Scotland, GPs could access and refer patients directly into the BTB programme, while in other areas, GPs had to refer patients to psychotherapy services where clinicians conducted assessments and then referred them to BTB while they were waiting for, or instead of, face-to-face therapy. In the case of this study, patients were referred into BTB by their GPs/clinicians. A BTB referral was then sent to a CCBT administrator/coordinator, who processed it and then posted or emailed appointment letters to patients. Depending on the locations, patients could be given access to BTB at a psychotherapy clinic, GP surgery, community centre, local library, hospital, or their home (e.g. if they lived in a remote location and if they had no or very low risk of suicidal tendencies) through an internet connection. If a home access option was available and given, patients would then be sent an email with a login password to access BTB online from home, although they still had to wait a couple of weeks to receive this email.

\section{Ethical approval and participant identification}

Ethical approval was granted by the NHS South East Scotland Research Ethics Committee and access permissions were obtained from Research and Development for the NHS research sites. Patients were sought who were offered BTB by the NHS services, as they would have firsthand user experiences and knowledge of the programme. These patients were recruited based on the following criteria: they were currently using or had used BTB within the past 18 months; they were 16 years of age or older; and English speaking.

Potential patients at the three NHS services within Scotland were identified by NHS coordinators from the records of patients who had been referred to BTB treatment for anxiety 
and depression. The coordinators then sent the study invitation letter and information sheet to the patients (those who were currently users, the completers and non-completers of the programme), inviting them to take part in the study. If individuals were interested and wished to participate, they were asked if they were prepared to be approached by the researcher (first author) and if they would prefer an email or face-to-face interview. Forty-one patients expressed willingness to participate in the study and were approached by the researcher. Of these, 33 (17 females and 16 males, whose ages ranged from 18 to 61, average age 42) decided to take part and completed the interview. It should be noted that the researcher had no information about those contacted by the NHS coordinators at the first point of approach and how many had declined the study invitation. In addition, because of ethical considerations and communication challenges, it was more difficult to follow up and invite patients who had dropped out. Only three out of the 33 patients had dropped out of the BTB programme before completion. Informed consent forms were collected from all patients before interviews were conducted. All patients responded to the set of interview questions for both face-to-face and email interviews.

\section{Interviews and procedure}

The first author conducted all the interviews. Seven patients wished to participate by email interview and 26 opted for a face-to-face interview. All face-to-face interviews took place at NHS sites, and most lasted around 45 minutes, and were digitally recorded. They were transcribed verbatim by a professional transcription service.

For the email interviews, to avoid overburdening patients, only three to four questions were sent to patients at any time. After receiving the email responses, these were compiled and analysed immediately to prepare for the next set of questions (e.g. with specific probes or new questions). Approximately five sets of email interview questions were sent to each patient. (The final number depended on the response to previous questions.) After the email interviews were completed, a summary was sent to patients, asking them to review and validate their responses.

\section{Analysis}

Interview data collection and data analysis took place concurrently by the first author. Data collection was continued until a saturation point [i.e. when the researcher believed that the collected information has answered the research questions and that it is enough to understand the situations or to tell a rich or coherent story (Braun and Clarke, 2013)] was reached. As the researcher's background can influence their data collection and interpretation of findings (Creswell, 2003), it is important to engage in a reflexive process of self-examination and to disclose the research process and the researcher's position in relation to the data: 'who am I in relation to the research?' (Pitard, 2017; p. 10). Therefore, authors' information is set out below to help readers form their own judgements of potential bias, although actions (e.g. reviews and discussions of analysis and findings) have been taken to prevent or minimise bias (Perera-Delcourt and Sharkey, 2019).

The first author undertook this qualitative study as part of a wider research degree. She has a background in information system development and software quality assurance engineering, and a keen interest in human-computer interaction (HCI), and user experience (UX) in medical devices research. She believes that good technological design can achieve better results and improve the quality of mental health care and its services. She was aware of the potential influence of this professional background in design, and the epistemological perspective that went with it (Karabeg, 2012). She was therefore mindful of her role and actions when conducting data collection and endeavoured not to be clouded or biased in her judgements of 
CCBT interventions or applications and the services implemented, but to stay close to patients' voices and experiences when reading over their interview transcriptions. In addition, she often sought advice from the co-authors during the data collection and when any ethical issues arose. The co-authors are the first author's research academic supervisors, who acted as the experts in the field and helped to guide and monitor the research process as well as to confirm the data interpretation, themes generated, and to verify the research findings.

All interview transcripts were manually coded and analysed by the first author in accordance with the six phases procedure of TA (Braun and Clarke, 2013; Clarke and Braun, 2014):

(1) Becoming familiar with and making sense of the data by reading and re-reading each interview transcript, noting down ideas and patterns, and writing a summary;

(2) Generating initial codes by highlighting and labelling each section of the transcript that captures something meaningful and interesting about the data, collating and matching the relevant data to every code;

(3) Searching for themes by examining across the coded data to generate potential themes and grouping them. At this stage, as suggested by Braun and Clarke (2013), a thematic map is also generated to help visualise the relationship and connection between themes and restructure them;

(4) Reviewing themes by checking them against data extracts to ensure that they are coherent, in logical order and supporting each other;

(5) Defining and naming the themes to help convey their subject matter; and

(6) Writing up the report by refining and finalising the analysis, and narrating a rich story of the data with generated themes and a sample of data extracts to demonstrate the findings.

For credibility and validity, the initial codes, potential themes, each phase of analysis, and drafts of writing up the report were repeatedly discussed, and reviewed by the co-authors.

It is also necessary to note that patient counts/numbers for each of the themes reported in the Results section are not included. This is because in qualitative research, frequencies are not regarded as important as they do not determine the salience of a topic (Braun and Clarke, 2013; Mason, 2010; Morse, 1995; Pyett, 2003): rather, 'the Richness of data is derived from detailed description, not the number of times something is stated. Frequency counts are out' (Morse, 1995; p. 148). Expressions such as 'many participants comment that...' (Braun and Clarke, 2013; p. 161) are therefore used for reporting.

\section{Results}

Six key themes were established which described patients' experiences when they were being referred to, informed about and given access to the BTB programme, and the challenges they faced: (1) information dissemination; (2) expectations and the impact of waiting for BTB; (3) impact of locations on experience of BTB; (4) preference for home access; (5) desire for better human support; and (6) desire for additional application support features. Each theme is illustrated with interview extracts as described below. The authors aimed to present representative extracts from all patients; those selected were the most verbally expressive, and which most closely represented the themes (Cooney et al., 2018).

\section{Theme 1 - Information dissemination: lack of knowledge about the method}

Most patients (PA) described how they were not fully informed by their GP about BTB. They mentioned that they only knew about BTB after their GP had referred them to this treatment. The information they received from their GP was that it was a CBT course carried out on a computer and that they would need to sit and work through it. Although a BTB information 
leaflet was mailed to them later, before they began the first session, there was still a lack of clarity about what the programme entailed, how it worked, and the actual method or rationale behind the approach. This made them feel sceptical about the programme and wonder if it was the right treatment for them. Additionally, they did not think that their GPs really knew much about BTB or that it was even an option. Some were even a little unsure if BTB was actually targeted at their level of anxiety/depression.

I got the information really when I got the initial appointment letter through ... He [GP] didn't give me anything ... I don't think the GP with his referral actually realised that 'Beating the Blues' would be an option .... It didn't convince me initially at all, no. In fact, I was quite unsure about it ... And that's actually why when I went to see the doctor, I actually took the letter and I said, 'is this really for me?' ... [PA29]

My impression was that it was aimed at people with a bit a more serious problems than what I had. [PA13]

Besides lacking information about BTB, patients also had to wait longer than they had expected to access the BTB programme. Their expectations and the impact of having to wait for BTB are examined in the next theme.

\section{Theme 2 - Expectations and the impact of waiting for BTB: having to seek alternative support} when computer treatment should have but failed to meet expectations of less or no waiting time

Most patients anticipated that there would be no waiting time or that the waiting time for BTB would be around 2-3 weeks at the most. However, in some NHS locations, they had to wait 6-8 weeks to get their first BTB appointment after being referred by their GP for BTB. To them, this was unacceptable, especially when they needed help urgently. However, the long waiting time was due to limited resources (e.g. rooms, computers) at some NHS clinics and local libraries. Although it was recommended to patients that they complete one session per week, they sometimes had to wait for available appointment slots and therefore could not complete on schedule. In addition, they felt that the NHS should have given them an alternative option such as doing BTB from home. This would have reduced the waiting times for BTB, increased the accessibility and availability of appointment slots, and would have enabled them to finish the programme sooner. Unfortunately, the home access option was not available at all NHS locations due to licence costs and resources.

... one way or another to make it available quicker ... Instead of waiting eight weeks. Now that might be that you do some of it online if you've got access at home and obviously a lot of people would have access at home and that would mean less people would have to go to the hospital. Maybe they'd need more computers ... [PA27]

If Beating the Blues was the sole option open to me then yes, I would have said that six weeks was too long to wait. Two to three weeks would be a better target. [PA30]

Even in some NHS locations where patients were given the option to do BTB from home, they still had to wait for some time due to referral and administrative processing delays before they could start the programme online.

I thought that my GP would refer me and then I would get the code. But the fact that I had to get the letter to sign stuff and then send it back, and then I got the code. I thought it would be a bit quicker than that ... [PA32] 
Importantly, patients felt that having access to BTB at the right time, when their problems were most acute, would have helped them to recover and return to their normal lives sooner, as some had to take time off work due to anxiety and depression. Instead, as access to BTB was delayed, some patients had to seek alternative forms of support.

My GP, she was quite anxious for me to start ... I was actually off work that was the only thing. Maybe I would have gone back to work quicker if I'd started the programme quicker... [PA20]

... There was a bit of a gap. Now because I had other support mechanisms; I was seeing the counsellor and things like that, it was okay. [PA27]

Furthermore, access given to BTB from different locations by the local health boards had a bearing on patients' experience, which is covered in the following theme.

\section{Theme 3 - Impact of locations on experience of BTB: doing BTB at the NHS clinics and local libraries}

Patients described their experience when given access to BTB at different locations. Access to CCBT, as mentioned previously, was based on the service model that each local health board chose to deliver. Therefore, patients might have different access to BTB, depending on their location. For instance, some patients might be given access to do it from home and/or at one of the NHS clinics (e.g. at a hospital's psychological therapy). Others might have no choice but to do it at a community centre or library. In this study, the majority of patients used BTB at NHS clinics, while others had to use it at their local library. For various reasons some patients did not mind doing BTB at the clinics. These reasons included the belief that being at the clinic helped them to be more self-disciplined, and it also allowed them to spend time away from their home and gave them the opportunity of meeting/talking to someone. However, patients who had to do BTB at local libraries detailed how vulnerable they felt when they had to work through BTB sessions in a public space or environment. In addition, concerns of stigmatisation, along with the lack of privacy and confidentiality also played a part.

\section{Experiencing BTB at an NHS clinic: getting out, actually doing it, having the human interaction}

For patients requiring a more structured approach, using BTB at the clinic offered a fixed schedule. They felt that doing it from home would require self-discipline and concentration. Additionally, they felt the importance of getting out of their comfort zone or away from home, especially if their problems related to the home environment.

... I think if you were to do it in the house you wouldn't take it in the same. But I think it's almost like going to a gym, you go into it for that specific thing and therefore you do it. It's done and it's like trying the exercise in front of the telly, you're not concentrating on what you're doing you know. So if I was in the house to do it I would have too many distractions. [PA04]

I actually quite enjoy coming here [NHS site]. It's a change of scenery. I think if it was accessible from home, for some people, it may be a good thing. But if you're suffering from high levels of depression maybe not. Because part of your own help is getting out, you know. Because even the doctor will say, 'get out, go for a walk, do something different, even if it's just for five minutes' ... [PA38] 
It should be noted that patients preferring the clinic environment also liked the personal or human interaction. Staff were there to welcome them and answer questions. This boosted their motivation in a way that interacting solely with a computer could not.

Coming to the site gives you the motivation like you walk in and somebody is expecting you to be here ... [PA10]

\section{Experiencing BTB at a library: feeling exposed, being stigmatised, difficulty concentrating, taking longer to complete}

In some locations, BTB was delivered at local libraries, even though this is a non-NHS/clinical setting and is a public environment where there could be concerns about privacy and confidentiality. Patients also found it hard to schedule a weekly BTB appointment at local libraries due to opening and closing times and personal commitments/childcare arrangements. This led to the programme taking longer than the recommended one session per week to complete. They felt they would have had better focus and less stress by not having to rearrange work and their daily routine to do BTB at the library.

I cannot remember the exact opening hours of the library I used, they were quite awkward and even if they were open after $5 \mathrm{pm}$, I could not attend any time after 3 due to childcare ... I took a long time to complete the course, almost seven months I think, as it was difficult fitting the sessions around work, childcare and the opening hours of the library. [PA16]

One of the crucial problems some patients mentioned was 'feeling exposed in the public space' when doing BTB at the library. One aspect of this related to their vulnerable feelings, which could be triggered by working on BTB sessions. In a public place, patients felt they had to try to control their emotions so that people would not see them displaying emotional reactions.

I was quite tearful sometimes when working on some of the sessions, was not pleasant sitting in a public exposed space crying... [PA16]

... I felt they could be looking at me and could see my reactions ... [PA17]

Another aspect related to data privacy and stigmatisation. Patients worried that someone might be able to see what they were working on at the computer. As anxiety and depression are associated with stigma, they felt that there was not enough privacy, space or comfort to work in the library. Furthermore, patients mentioned that the library they attended had no private places allocated specifically for people doing BTB. There were also no dividers between the computers. They had to take extra steps to guard their privacy: looking for a discreet place to sit to do BTB, adjusting the computer screen so it would be hard for someone to see what was on the screen, or try to be at the printer quickly to collect the print-outs before someone else might look at them.

... I printed it all out at the end and I was there as it came off the printer ... I was concerned that people around me might have their eye caught by my work sheets. Every session I completed took place at a table for two, there was no divider between myself and the other PC. It was also in quite a prominent place in the library. I felt quite obvious. [PA16]

The library has 12 workstations based around three large work areas, so there was good elbow room, but I would sit next to the window, so if someone sat in the next workstation I would adjust my screen for more privacy. [PA21] 
Besides 'feeling exposed' and lacking privacy, patients felt they were being rushed by the constant reminder from the countdown timer software installed on the library computers of how much time they had left to complete the session. The software would automatically log them out when time was up. These library machines were for public use and the provision of access to them was not designed specifically for clinical need. Although the BTB programme's aim was to help patients manage and reduce stress, the countdown timer made them more anxious and impaired their concentration. It should also be noted that the BTB programme was supposed to last 60 minutes per session. However, patients actually needed extra time to complete a session.

... in the library I did the course [but] sessions on the PC were limited to 60 minutes, I found this quite limiting and I may have rushed [through] some of the stuff through fear of not completing the whole session in the 60 minutes. [PA16]

The lack of time for completing BTB sessions was also mentioned at some NHS clinics where resources (computer/room) were limited. Patients did not feel they had enough time to complete the session especially if they arrived late.

... I came one day and I was running late actually and [coordinator] said, 'well I've got somebody else waiting, so could you be finished by twenty past ten' or something like that because they were waiting to come on and it was like a chain. A conveyor belt kind of thing. One finishes and the next one comes in... [PA14]

However, patients completing BTB at one clinic were given plenty of time to work on the session and were also reassured about taking as much time as they wished even when they were late.

[Coordinator] has been quite good about time and everything. I think [coordinator] was actually held on a little bit late so I could get finished. So it wasn't a case of you know, you need to get out, get moving, hurry up. [PA26]

Most patients in the study would have preferred to do BTB from home if this option had been made available to them as described in the next theme.

Theme 4 - Preference for home access: doing BTB from home is more comfortable, giving both flexibility and privacy

Most patients would have preferred to do BTB from home instead at clinics or libraries, if they had been given this option, as the environment would have been more private (especially when feeling low/tearful), comfortable, and they could focus better than in a public space. Moreover, they would not have to leave work early or explain why they were leaving early (most clinics were only open from 9 a.m. to 5 p.m.).

... As I had to go to hospital every week as well as my GP every few weeks and then the CBT counsellor, I felt there were too many times I had to arrange my work around so in the end I told my team colleagues rather than trying to keep coming up with excuses for late starts/ early finishes. That was ok in my case but I may have preferred not to disclose to them. Doing it at home would let me do [it] at a time that suits ... [PA19] 
I definitely think so because, as it currently stands as the place I go to is only open approx.

9 am-5 pm on weekdays, it means I have to miss work to attend. This seems to cause more anxiety than it cures. [PA18]

The previous sections offered insights into how patients had different experiences at different locations and their preferences regarding the access options. They also narrated their experiences about the level of support provided when doing BTB at the locations, their expectations, and what kind of support would have helped them. These are covered in the following theme.

Theme 5 - Desire for better human support: having someone to check in or give some support while doing the progamme

Patients described their experiences about the support they received when doing BTB at NHS clinics and local libraries. Their views on the level of human support that they expected or desired to have for this self-help treatment included views on the support from the health professionals (e.g. GPs/clinicians) and support staff (administrators/coordinators).

Depending on the CCBT model that the local health board had implemented, its support mechanisms could vary between different locations. Hence patients might have a different experience in the services and support offered for CCBT. In this study, patients in one clinic had very good experiences and described how happy they were with the service and support they received, especially from the friendly CCBT coordinator. They were given plenty of attention: someone was there to greet and welcome them and offered tea/coffee before starting the BTB session. Additionally, he/she would always spend time talking to them, asking them how their week had been, and checking if they had any queries or concerns about the programme before or after the BTB session.

... We tend to have had a discussion on the way in. Or when the session has finished. I would say [coordinator] is very diligent, particularly after the session has finished, about asking if you have any questions or if there are any parts that you weren't sure about. [PA29]

Some patients looked forward to talking to the coordinator. This suggests the personal interaction with the coordinator was pivotal and potentially served a therapeutic purpose.

I felt it was helpful for me ... we would kind of make a cup of tea and we just have a hello and how do you do. [Coordinator] is very good, and we would just talk ... and then I thought, 'actually we missed two sessions because we just talked'... [PA24]

Conversely, patients who were doing BTB at local libraries had no direct contact with the CCBT coordinator. They had to call or email him/her for any inquiry. One patient described his experience when trying to contact her/him as like playing a lottery.

... whenever I phoned up [coordinator] was never there and even though I left a message [coordinator] didn't always get back to me. It was always a bit of a lottery trying to get hold of [coordinator]. In the end I just lost the motivation to call [coordinator] ... [PA25]

Other patients who completed BTB at a clinic also experienced lack of support. They first met the coordinator who then took them to the BTB room. They were then on their own for the entire session and were told to leave at the end of the session without seeing the coordinator again.

My instructions were, 'once you're finished just log off and you can go'. [PA14] 
Most patients would have valued someone being there to check them in and also to give them emotional support or motivation, even if only ten minutes at the end of the session to see how they were. This was especially true as after working on some of the BTB sessions a patient's mood could change, causing them distress. They would not wish to go home in tears and in a very upset state.

I think if somebody always came in at the end, just to say 'so how are things?'. Because at the very beginning I was told [by admin staff] that I could always chat to somebody here at the end. They couldn't help me with my situation but it would just be a listening ear... And I think on one particular day when I felt really pretty bad leaving, I thought 'well I'll have a look in the reception and see if I can see the person that I normally spoke to', and everyone had their heads down and was really busy and I thought 'oh, I'll not bother anybody'. So I went home ... [PA11]

The above patient also described how she had wished to talk to someone after completing a difficult session. However, when finding staff concentrating on their tasks, she lost confidence and refrained from seeking help. This seems to present a real challenge to the CCBT approach, because human contact appears to be very important.

I could go to reception and ask to speak to ... I can't remember the woman's name. But the person that took me in ... But I think on that occasion just the circumstances; I probably wasn't feeling particularly confident just with where I was at. And that's the whole thing with anxiety and depression, your confidence very often goes to pot. So when I looked in at reception and saw that everybody seemed very busy there was that barrier up and I thought, 'no I'll not bother'. [PA11]

In addition, most patients also felt the need to have some support from health professionals while working on the BTB programme. This would help to give them confidence and reassurance that they were making progress with the programme. Most commented that although they were referred to BTB by their GP, they did not know whether their GP would follow up with them on their progress. However, they hoped that their GP would do so, to discuss their progress and to compare their symptoms before and after the BTB programme, and to talk about the next steps in their treatment plan.

I mean I do think that it will be discussed at some point with my GP ... She's referred me ... you know. [PA34]

However, it should be noted that support or interaction between patients and GPs would depend on the doctor-patient relationship. Some patients had good experiences and were happy that their GP motivated them to do BTB and talk about their progress. Others felt that their GP did not follow up or have time for them and suggested medication as a fast resolution to their anxiety and depression problems.

A lot of doctors are just like well, 'take a tablet, you'll be fine'. They don't have time I think, to listen now. Because it's usually a ten minutes appointment and you're maybe in there with two or three things ... [PA23]

In addition to wishing for some human support, most patients also wanted to have some builtin application support features within the programme that could assist them with any queries and concerns that they might have while doing the programme. These are examined in the next theme. 
Theme 6 - Desire for additional application support features: giving opportunity to clarify, explain or provide feedback

Most patients mentioned that additional support features within the application itself could be particularly useful when they were unsure about the techniques (e.g. 'PIG Beliefs' and the 'Downward Arrow'1) or whether they were doing the right thing. Patients often felt frustrated when they could not explain how they felt to the computer, seek clarification about the session and/or give further explanation to the answers given. For instance, they had to respond to questions about suicidal thoughts at the beginning of every BTB session. However, they felt that there should have been a better indicator of how serious these thoughts were, or an empty box provided so that they could explain why they answered 'yes'. This would avoid sending a false alarm to their GP and would allow them to respond truthfully without fear of consequences for answering yes.

... It's very frustrating when the programme continues as if you understand everything and when you don't, there's nothing you can do about it. [PA17]

I mean if you're putting 'no' down that means you've not had any feelings. But if you've maybe had some ... you could maybe put down 'yes', and instead of alarm bells going with your doctor ... Yes, maybe a wee box or something you can just write a comment. [PA40]

\section{Discussion}

This paper explores qualitative data on patients' experiences and acceptance of one CCBT programme delivering computer-assisted therapy (Beating the Blues, BTB) provided by the NHS across Scotland. The study's findings underline multiple challenges, not only related to the implementation and delivery of BTB, but also to the support required and design features of this application. Patients had little or no knowledge about the CCBT approach and/or BTB programme when being referred by their GPs/clinicians. In addition, access to BTB and the support provided were varied across locations, which worked for some patients but not everyone. For instance, some patients would have preferred accessing BTB at home instead of doing it at the library if it was available to them. Most patients also desired some additional built-in support features within the BTB programme that would provide them the options to search for definitions/explanations of the terms and techniques used in BTB's modules, and also to clarify, explain, or raise any concern that they might have.

Disseminating CCBT information to patients is essential in promoting its use, as the acceptability of CCBT treatment services depends 'on the degree of awareness of their existence and the quality of information available to patients and professionals' (ApolinarioHagen et al., 2018; p. 142). Most patients in this study were not well informed about the BTB programme, leading them to have doubts about this therapeutic intervention. Previous studies have also shown that patients did not know what to expect from CCBT, even when their GPs had been reminded to inform patients about the nature of this therapy (Bennett et al., 2008; Fox et al., 2004). Moreover, insufficient information for patients can lead to inappropriate referrals (Bennett et al., 2008) or an incorrect match between patients and programmes (Folker et al., 2018). The reasons that patients were not well informed about CCBT could be because their GPs were ill-informed, unaware, and/or sceptical about the programme (Andersson et al., 2019; Breedvelt et al., 2019; Du et al., 2013).

Patients in this study also experienced variable waiting times for BTB and some, who were not able to access BTB when they most needed help, had to look for other support mechanisms. Long

\footnotetext{
${ }^{1 ‘}$ PIG Beliefs' and 'Downward Arrow' are BTB’s cognitive techniques.
} 
waiting times related to the referral process and the lack of resources (e.g. rooms, computers) to accommodate patients' appointments. Access to BTB from home was also not an option in some NHS regions. Patients had not expected these waiting times. Indeed, the aim of CCBT is to increase accessibility and flexibility of therapy treatment especially in times of need, and to eliminate waiting times. Some patients also took months instead of weeks to complete the BTB sessions, due to the hours of operation of the NHS clinics and local libraries, which conflicted with their personal commitments and standard working hours. Attending CCBT during regular office hours proved to be a challenge (Titov et al., 2010) and was a reason for withdrawing from the treatment (Bennett et al., 2008) in previous studies. Researchers also noted that a GP's referral of a patient for CCBT could take a month and suggested that selfreferral would be a much faster option. It would also help to improve accessibility of CCBT services (Folker et al., 2018; Titov et al., 2018).

Furthermore, patients in this study described how unpleasant it was, sitting exposed in a public library while engaging with the BTB session. They feared that what they were doing would be noticed, and they might be seen crying or showing emotional distress. While anonymity, selfpace and privacy have been highlighted as positives of CCBT (Andrews et al., 2010; Clarke et al., 2015), doing CCBT in a public space may not be appealing due to stigma and privacy concerns. Similar concerns about lack of privacy when using public-access computers have also been voiced by patients in recent research (Health Quality Ontario, 2019). It is therefore worth noting that public spaces such as libraries are not clinical and therapeutic settings. Hence, privacy, confidentiality and the avoidance of social stigma could be compromised in these settings. Green and Iverson (2009) warned that best ethical practices are necessary to ensure that the confidentiality and safety of patients are protected, and that clinicians need to ascertain that private rooms are available for delivering CCBT. Moreover, from an ethical perspective of respecting individuals' rights, service providers may have the responsibility to offer patients a choice regarding access to CCBT, where they have a strong preference as to what is most suitable for them (Day et al., 2013). Besides, library computers are for public access and time allowed on these computers could be limited. Patients in this study also felt anxious and distracted by libraries' computer timer software, which made them rush to finish the sessions. Mood and anxiety may affect programme engagement, as high anxiety can produce poor concentration, while low mood can reduce motivation to complete a session (Donkin and Glozier, 2012). Therefore, if patients were unable to concentrate, becoming more anxious and unable to reflect on CCBT sessions due to the countdown timer software, this would seem to defeat the rationale for CCBT treatment and hamper its effectiveness. An important question is whether or not the delivery of BTB (or CCBT more broadly) in a public setting is appropriate at all.

The lack of human support and contact, especially with self-guided CCBT, has been recognised as a substantial drawback (Health Quality Ontario, 2019). This has also affected user engagement (Batterham et al., 2018) and may account for the low adaptability and acceptability of CCBT (Hadjistavropoulos et al., 2017; Knowles et al., 2015). In this study, support staff for CCBT varied between locations. In one clinic, patients received plenty of attention, while for those who did BTB at local libraries or at another clinic, support was minimal or absent. Most patients expressed a wish to have some support (emotional, check-in, programme content clarifying) while using BTB. Personal contact from CCBT support staff, and/or review meetings with GP/clinicians in between BTB sessions would help to motivate and reinforce what they had learned. Gega et al. (2013), who examined patients' experiences of self-help CCBT $v s$ therapist-delivered, also emphasised that the absence of contact between a patient and therapist/other staff member led to misunderstandings or to patients' avoiding the completion of the therapeutic tasks (e.g. homework). As suggested, all interventions, to be 
fully effective, need some form of human support (Kaltenthaler and Cavanagh, 2010). Even if a staff member took only 5-10 minutes per session to provide assistance (Marks and Cavanagh, 2009), this could impact user engagement (Batterham et al., 2018; Davies et al., 2014). Furthermore, recent studies have demonstrated that a successful implementation model for delivering CCBT in clinics has involved therapist support (Hadjistavropoulos et al., 2017; Titov et al., 2018). Programmes have also been tailored using media-rich interactive content incorporating engaging strategies to improve user experience (Richards et al., 2018). A successful CCBT application therefore must be designed to adapt to and accommodate users' needs. For instance, in this study, most patients voiced their frustrations at not having some built-in support features within the BTB application. Patient feedback concerning programme features is essential and therefore, it would be valuable if their perceptions were reported more frequently in the literature; they can influence the usefulness of the application and be helpful to others (e.g. practitioners), and especially designers and developers who need to be mindful of and factor in users' concerns when designing CCBT or applications that support mental health interventions (Doherty et al., 2010).

In sum, this qualitative study's findings demonstrate that there are challenges to the delivery of CCBT services (e.g. the BTB programme) that affect patients accessing this computer-aided psychotherapy. As there are different methods of delivering CCBT across the UK, there are still questions about which service model is most effective and how best to disseminate CCBT (Folker et al., 2018; Kenicer et al., 2012). As suggested by researchers, it is pivotal to examine different implementation models (Hadjistavropoulos et al., 2017) to compare what does and does not work, to understand patients' preferences (Beattie et al., 2009), and to comprehend the type and level of support provided (Stefanopoulou et al., 2019). Additionally, clinicians, staff, and non-mental health professionals need to be better trained and educated to support and deliver CCBT (Kuosmanen et al., 2018; Lal, 2019). The quality of the design of CCBT applications is also an important consideration.

\section{Strengths and limitations}

The qualitative data presented were collected from NHS primary care, adding to the value and extending the scope of existing studies of CCBT implementation in routine care settings. It is an adequate sample size to provide deeper understanding of patients' experiences (Hadjistavropoulos et al., 2018), and data saturation was also attained. In addition, this study complements research concerning the constraints on implementation of CCBT services (Folker et al., 2018), and might shed light on potential reasons for poor engagement of patients (Apolinario-Hagen et al., 2017) and high drop-out rates.

There are several limitations. These qualitative data relate to the BTB UK version and not the recent US version that has been updated and is currently used in NHS services. Although the UK version interface is different from the US one, the programme's concept is still similar. This paper's main concerns are CCBT implementation and the services delivered to patients, focusing particularly on their views and experiences relating to referral and access to the treatment, the level of staff support and features of BTB programme. It is also worth noting that the pace of change in technology is rapid, and new versions of applications are released before studies can be published. This has been the case with this qualitative study which was further compounded by the time lag and unexpected factors and challenges between research completion and publication (Abu Rahal et al., 2018). However, the BTB programme is still currently available to patients at community locations (i.e. libraries) and at home (Dumfries \& Galloway Health \& Social Care, 2021; Fife Health \& Social Care Partnership, 2021). For this reason and because these data were drawn from a Scottish population, this study is still deemed relevant to CCBT implementation literature. It may offer useful evidence in countries where computer aid is still in its early stages and/or not readily available to everyone, 
especially to those who may not have the means to pay for any therapy, or even have access to a computer and/or internet to do it from home. The study was also limited to one CCBT package (BTB) and the majority of patients were from one clinic. Only three patients out of the 33 who withdrew from the BTB programme could be recruited. Moreover, as the recruitment was dependent on the help and availability of the NHS coordinators to identify participants and also because of ethical reasons, it was difficult to follow up and invite patients who had dropped out. This leaves room for future studies, which may wish specifically to recruit those who have dropped out and/or who were given access to CCBT but did not wish to take up this treatment. Furthermore, future research should involve different groups of patients (including drop-outs), who have done CCBT in different settings (e.g. libraries, community centres), and with different CCBT packages. There is also scope for evaluation of issues such as: technological infrastructure and resources, staff training/support, how CCBT is made available to patients at different NHS clinics, waiting times, and the design and usability of the applications.

\section{Clinical implications, future directions and conclusions}

This paper points to the need for the health policymakers in the UK and perhaps countries across the world to focus on how best to deliver CCBT to patients in routine care. As different service models are used in the NHS, this may indicate a need to implement a standardised approach/model to deliver CCBT. As public settings, such as libraries, can affect patients' engagement and create unnecessary stress, policymakers may consider delivering CCBT in more private settings, and in addition having some degree of support from GPs and/or support staff. Perhaps some training in therapeutic support and delivery of CCBT could be provided to non-mental health professionals, such as librarians, who may not need clinical experience to offer a kind gesture and empathetic words (e.g. asking how patients are doing or offering tea/biscuits when they come for CCBT sessions). Such interactions could help to change the user experience. Further research on librarian assistance is pivotal if $\mathrm{BTB} / \mathrm{CCBT}$ is to continue to be delivered in library settings. In addition, CCBT applications need to be enhanced to incorporate support features tailored to increase user motivation and engagement (Richards et al., 2018). On this note, CCBT researchers might wish to draw on HCI research (Doherty et al., 2010) and its evaluation methods. These have been widely adopted to support better system designs and solutions to meet users' requirements and expectations. Critical steps should also be taken to evaluate the applications, usability and broader context of use. All of these are essential to the success of CCBT implementation and would merit the attention of healthcare policymakers and professionals.

Key practice points

(1) Services offering CCBT need to improve the knowledge of those making referrals to it.

(2) Patient preference should be taken into account when offering CCBT.

(3) Practitioners and services should provide patients with full information about the CCBT programme, what this treatment involves, and the approximate length of the waiting time to gain access to it.

(4) Services should follow best practice guidelines for implementation of CCBT.

(5) Staff providing support to CCBT should establish a therapeutic relationship with patients to encourage and enhance their engagement with treatment.

(6) Public spaces such as libraries may not be the right places to deliver CCBT due to ethical challenges, and may affect patients' mood and increase anxiety levels, which in turn may hamper the effectiveness of CCBT treatment and delivery.

(7) Built-in support features and their usability are essential to user experience of the CCBT programme and positive responses to the intervention. 
Acknowledgements. The authors wish to thank the participants for their involvement and valuable contribution to the study, and the NHS Scotland collaborators and administrative staff for all their support and assistance throughout the study.

Financial support. This research received no specific grant from any funding agency, commercial or not-for-profit-sectors.

Conflicts of interest. None.

Ethics statements. Authors have abided by the Ethical Principles of Psychologists and Code of Conduct as set out by the BABCP and BPS. In line with this, ethical approval was sought and approved by South-East Scotland Research Ethics (REC reference: $11 / \mathrm{AL} / 0183)$.

Data availability statement. The data are not publicly available due to privacy and ethical restrictions.

Author contributions. The first author designed and implemented the research, including data collection and analysis, and took the lead in writing the manuscript. The second and third authors guided and monitored the research process, confirmed the data interpretation, themes generated and verified the research findings. All authors contributed to the review and revision of the manuscript and approved the final version for publication.

\section{Further reading}

Doherty, G., Coyle, D., \& Matthews, M. (2010). Design and evaluation guidelines for mental health technologies. Interacting with Computers, 22, 243-252.

Folker, A. P., Mathiasen, K., Lauridsen, S. M., Stenderup, E., Dozeman, E., \& Folker, M. P. (2018). Implementing internetdelivered cognitive behavior therapy for common mental health disorders: a comparative case study of implementation challenges perceived by therapists and managers in five European internet services. Internet Interventions, 11, 60-70.

Gega, L., Smith, J., \& Reynolds, S. (2013). Cognitive behaviour therapy (CBT) for depression by computer vs. therapist: patient experiences and therapeutic processes. Psychotherapy Research, 23, 218-231.

Kenicer, D., McClay, C. A., \& Williams, C. (2012). A national survey of health service infrastructure and policy impacts on access to computerised CBT in Scotland. [Research Support, Non-U.S. Gov't]. BMC Medical Informatics and Decision Making, 12, p 102. doi: 10.1186/1472-6947-12-102

Lal, S. (2019). E-mental health: promising advancements in policy, research, and practice. Healthcare Management Forum, 32, 56-62. doi: 10.1177/0840470418818583

\section{References}

Abu Rahal, Z., Vadas, L., Manor, I., Bloch, B., \& Avital, A. (2018). Use of information and communication technologies among individuals with and without serious mental illness. Psychiatry Research, 266, 160-167. doi: 10.1016/j.psychres.2018. 05.026

Andersson, G., Titov, N., Dear, B. F., Rozental, A., \& Carlbring, P. (2019). Internet-delivered psychological treatments: from innovation to implementation. World Psychiatry, 18, 20-28. doi: 10.1002/wps.20610

Andrews, G., Basu, A., Cuijpers, P., Craske, M. G., McEvoy, P., English, C. L., \& Newby, J. M. (2018). Computer therapy for the anxiety and depression disorders is effective, acceptable and practical health care: an updated meta-analysis. Journal of Anxiety Disorders, 55, 70-78. doi: 10.1016/j.janxdis.2018.01.001

Andrews, G., Cuijpers, P., Craske, M. G., McEvoy, P., \& Titov, N. (2010). Computer therapy for the anxiety and depressive disorders is effective, acceptable and practical health care: a meta-analysis. PLOS One, 5, 1-6. doi: 10.1371/journal.pone. 0013196

Apolinario-Hagen, J. (2019). Internet-delivered psychological treatment options for panic disorder: a review on their efficacy and acceptability. Psychiatry Investigations, 16, 37-49. doi: 10.30773/pi.2018.06.26

Apolinario-Hagen, J., Fritsche, L., Bierhals, C., \& Salewski, C. (2018). Improving attitudes toward e-mental health services in the general population via psychoeducational information material: a randomized controlled trial. Internet Interventions, 12, 141-149. doi: 10.1016/j.invent.2017.12.002

Apolinario-Hagen, J., Vehreschild, V., \& Alkoudmani, R. M. (2017). Current views and perspectives on e-mental health: an exploratory survey study for understanding public attitudes toward internet-based psychotherapy in Germany. JMIR Mental Health, 4, e8. doi: 10.2196/mental.6375

Bakker, D., \& Rickard, N. (2019). Engagement with a cognitive behavioural therapy mobile phone app predicts changes in mental health and wellbeing: MoodMission. Australian Psychologist, 54, 245-260. doi: https://doi.org/10.1111/ap.12383

Barak, A., \& Grohol, J. M. (2011). Current and future trends in internet-supported mental health interventions. Journal of Technology in Human Services, 29, 155-196. 
Batterham, P. J., Calear, A. L., Farrer, L., McCallum, S. M., \& Cheng, V. W. S. (2018). FitMindKit: randomised controlled trial of an automatically tailored online program for mood, anxiety, substance use and suicidality. Internet Interventions, 12, 91-99. doi: https://doi.org/10.1016/j.invent.2017.08.002

Beattie, A., Shaw, A., Kaur, S., \& Kessler, D. (2009). Primary-care patients' expectations and experiences of online cognitive behavioural therapy for depression: a qualitative study. Health Expectations, 12, 45-59. doi: 10.1111/j.1369-7625.2008. 00531.x

Bennett, M., Harris, N., \& Rai, S. (2008). Banishing the blues. Mental Health Practice, 12, 32-36. doi: 10.7748/mhp2008.10. 12.2.32.c7711

Braun, V., \& Clarke, V. (2013). Successful Qualitative Research: A Practical Guide for Beginners. London, UK: Sage Publications.

Braun, V., \& Clarke, V. (2006). Using thematic analysis in psychology. Qualitative Research in Psychology, 3, 77-101. doi: 10.1191/1478088706qp063oa

Breedvelt, J. J., Zamperoni, V., Kessler, D., Riper, H., Kleiboer, A. M., Elliott, I., . . \& Bockting, C. L. (2019). GPs' attitudes towards digital technologies for depression: an online survey in primary care. British Journal of General Practice, 69, e164-e170. doi: 10.3399/bjgp18X700721

Brown, N., \& Stockman, T. (2013) Examining the use of thematic analysis as a tool for informing design of new family communication technologies. Paper presented at the Proceedings of the 27th International BCS Human Computer Interaction Conference, London, UK.

Christensen, H., Batterham, P. J., \& Calear, A. L. (2014). Online interventions for anxiety disorders. Current Opinion in Psychiatry, 27, 7-13. doi: 10.1097/YCO.0000000000000019

Clarke V., Braun V. (2014) Thematic analysis. In Michalos A.C. (ed), Encyclopedia of Quality of Life and Well-Being Research. Dordrecht, Netherlands: Springer. https://doi.org/10.1007/978-94-007-0753-5_3470

Clarke, A. M., Kuosmanen, T., \& Barry, M. M. (2015). A systematic review of online youth mental health promotion and prevention interventions. Journal of Youth and Adolescence, 44, 90-113. doi: 10.1007/s10964-014-0165-0

Collins, S., Byrne, M., Hawe, J., \& O'Reilly, G. (2018). Evaluation of a computerized cognitive behavioural therapy programme, MindWise (2.0), for adults with mild-to-moderate depression and anxiety. British Journal of Clinical Psychology, 57, 255-269. doi: 10.1111/bjc.12165

Cooney, P., Jackman, C., Tunney, C., Coyle, D., \& O'Reilly, G. (2018). Computer-assisted cognitive behavioural therapy: the experiences of adults who have an intellectual disability and anxiety or depression. Journal of Applied Research in Intellectual Disabilities, 31, 1032-1045. doi: 10.1111/jar.12459

Creswell, J. W. (2003). Research Design Qualitative, Quantitative and Mixed Methods Approaches (3rd edn). Los Angeles, CA, USA: Sage Publications.

Davies, E. B., Morriss, R., \& Glazebrook, C. (2014). Computer-delivered and web-based interventions to improve depression, anxiety, and psychological well-being of university students: a systematic review and meta-analysis. Journal of Medical Internet Research, 16, e130-e130. doi: 10.2196/jmir.3142

Day, V., McGrath, P. J., \& Wojtowicz, M. (2013). Internet-based guided self-help for university students with anxiety, depression and stress: a randomized controlled clinical trial. Behaviour Research and Therapy, 51, 344-351. doi: 10. 1016/j.brat.2013.03.003

Doherty, G., Coyle, D., \& Matthews, M. (2010). Design and evaluation guidelines for mental health technologies. Interacting with Computers, 22, 243-252. doi: https://doi.org/10.1016/j.intcom.2010.02.006

Donkin, L., \& Glozier, N. (2012). Motivators and motivations to persist with online psychological interventions: a qualitative study of treatment completers. Journal of Medical Internet Research, 14, e91. doi: 10.2196/jmir.2100

Du, E., Quayle, E., \& Macleod, H. (2013). Service providers' perceptions on the uptake of computerised cognitive behavioural therapy (CCBT). PsychNology Journal, 11, 213-233.

Dumfries \& Galloway Health \& Social Care (2021). Computerised Cognitive Behaviioural Therapy (cCBT). Retrieved from: https://dghscp.co.uk/ccbt/

Fife Health \& Social Care Partnership (2021). Access Therapies Fife. Retrieved from: https://www.accesstherapiesfife.scot. nhs.uk/beating-the-blues/

Folker, A. P., Mathiasen, K., Lauridsen, S. M., Stenderup, E., Dozeman, E., \& Folker, M. P. (2018). Implementing internetdelivered cognitive behavior therapy for common mental health disorders: a comparative case study of implementation challenges perceived by therapists and managers in five European internet services. Internet Interventions, 11, 60-70. doi: 10.1016/j.invent.2018.02.001

Fox, E., Acton, T., Wilding, B., \& Corcoran, J. S. (2004). Service development report: an assistant psychologist's perspective on the use of computerised cognitive behavioural therapy in a GP practice in Barnet. Quality in Primary Care, 12, pp. 165-169.

Gega, L., Smith, J., \& Reynolds, S. (2013). Cognitive behaviour therapy (CBT) for depression by computer vs. therapist: patient experiences and therapeutic processes. Psychotherapy Research, 23, pp. 218-231. 
Gega, L., Swift, L., Barton, G., Todd, G., Reeve, N., Bird, K., . . \& Molle, J. (2012). Computerised therapy for depression with clinician vs. assistant and brief vs. extended phone support: study protocol for a randomised controlled trial. Trials, 13, 151. doi: 10.1186/1745-6215-13-151

Gellatly, J., Chisnall, L., Seccombe, N., Ragan, K., Lidbetter, N., \& Cavanagh, K. (2018). @Home eTherapy service for people with common mental health problems: an evaluation. Behavioural Cognitive Psychotherapy, 46, 115-120. doi: $10.1017 /$ s1352465817000297

Gilbody, S., Littlewood, E., Hewitt, C., Brierley, G., Tharmanathan, P., Araya, R., . . \& White, D. (2015). Computerised cognitive behaviour therapy (cCBT) as treatment for depression in primary care (REEACT trial): large scale pragmatic randomised controlled trial. BMJ, 351, h5627. doi: 10.1136/bmj.h5627

Green, K. E., \& Iverson, K. M. (2009). Computerized cognitive-behavioral therapy in a stepped care model of treatment. Professional Psychology: Research and Practice, 40, 96-103. doi: 10.1037/a0012847

Hadjistavropoulos, H. D., Faller, Y. N., Klatt, A., Nugent, M. N., Dear, B. F., \& Titov, N. (2018). Patient perspectives on strengths and challenges of therapist-assisted internet-delivered cognitive behaviour therapy: using the patient voice to improve care. Community Mental Health Journal, 54, 944-950. doi: 10.1007/s10597-018-0286-0

Hadjistavropoulos, H. D., Nugent, M. M., Dirkse, D., \& Pugh, N. (2017). Implementation of internet-delivered cognitive behavior therapy within community mental health clinics: a process evaluation using the consolidated framework for implementation research. BMC Psychiatry, 17, 331. doi: 10.1186/s12888-017-1496-7

Hawkins, J. (2018). The practical utility and suitability of email interviews in qualitative research. The Qualitative Report, 23, 493-501.

Health Quality Ontario (2019). Internet-delivered cognitive behavioural therapy for major depression and anxiety disorders: a health technology assessment. Ontario Health Technology Assessment Series, 19, 1-199.

James, N. (2016). Using email interviews in qualitative educational research: creating space to think and time to talk. International Journal of Qualitative Studies in Education, 29, 150-163. doi: 10.1080/09518398.2015.1017848

Kaltenthaler, E., \& Cavanagh, K. (2010). Computerised cognitive behavioural therapy and its uses. Progress in Neurology and Psychiatry, 14, 22-29. doi: 10.1002/pnp.163

Karabeg, D. (2012). Design epistemology. Information, 3, 621-634. MDPI AG. Retrieved from: http://dx.doi.org/10.3390/ info3040621

Karyotaki, E., Riper, H., Twisk, J., Hoogendoorn, A., Kleiboer, A., Mira, A., . . \& Cuijpers, P. (2017). Efficacy of selfguided internet-based cognitive behavioral therapy in the treatment of depressive symptoms: a meta-analysis of individual participant data. JAMA Psychiatry, 74, 351-359. doi: 10.1001/jamapsychiatry.2017.0044

Kenicer, D., McClay, C. A., \& Williams, C. (2012). A national survey of health service infrastructure and policy impacts on access to computerised CBT in Scotland. [Research Support, Non-U.S. Gov't]. BMC Medical Informatics and Decision Making, 12, 102. doi: 10.1186/1472-6947-12-102

Kessler, R. C., Berglund, P., Demler, O., Jin, R., Koretz, D., Merikangas, K. R., .. \& Wang, P. S. (2003). The epidemiology of major depressive disorder: results from the National Comorbidity Survey Replication (NCS-R). JAMA, 289, 3095-3105. doi: 10.1001/jama.289.23.3095

Kivi, M., Eriksson, M. C. M., Hange, D., Petersson, E.-L., Björkelund, C., \& Johansson, B. (2015). Experiences and attitudes of primary care therapists in the implementation and use of internet-based treatment in Swedish primary care settings. Internet Interventions, 2, 248-256. doi: https://doi.org/10.1016/j.invent.2015.06.001

Knowles, S. E., Lovell, K., Bower, P., Gilbody, S., Littlewood, E., \& Lester, H. (2015). Patient experience of computerised therapy for depression in primary care. BMJ Open, 5, e008581. doi: 10.1136/bmjopen-2015-008581

Kraus, C., Kadriu, B., Lanzenberger, R., Zarate Jr, C. A., \& Kasper, S. (2019). Prognosis and improved outcomes in major depression: a review. Translational Psychiatry, 9, 127. doi: 10.1038/s41398-019-0460-3

Kuosmanen, T., Fleming, T. M., \& Barry, M. M. (2018). The implementation of SPARX-R computerized mental health program in alternative education: exploring the factors contributing to engagement and dropout. Children and Youth Services Review, 84, 176-184. doi: https://doi.org/10.1016/j.childyouth.2017.11.032

Lal, S. (2019). E-mental health: promising advancements in policy, research, and practice. Healthc Manage Forum, 32, 56-62. doi: $10.1177 / 0840470418818583$

Low, N. C. P., Cui, L., \& Merikangas, K. R. (2008). Community versus clinic sampling: effect on the familial aggregation of anxiety disorders. Biological Psychiatry, 63, 884-890. doi: https://doi.org/10.1016/j.biopsych.2007.08.011

Marks, I., \& Cavanagh, K. (2009). Computer-aided psychological treatments: evolving issues. Annual Review of Clinical Psychology, 5, 121-141. doi: 10.1146/annurev.clinpsy.032408.153538

Mason, M. (2010). Sample size and saturation in PhD studies using qualitative interviews. Forum: Qualitative Social Research, 11.

McCrone, P., Knapp, M., Proudfoot, J., Ryden, C., Cavanagh, K., Shapiro, D. A., . . \& Tylee, A. (2004). Cost-effectiveness of computerised cognitive-behavioural therapy for anxiety and depression in primary care: randomised controlled trial. British Journal of Psychiatry, 185, 55-62.

McMurchie, W., Macleod, F., Power, K., Laidlaw, K., \& Prentice, N. (2013). Computerised cognitive behavioural therapy for depression and anxiety with older people: a pilot study to examine patient acceptability and treatment outcome. International Journal of Geriatric Psychiatry, 28, 1147-1156. doi: 10.1002/gps.3935 
Meho, L. (2006). E-mail interviewing in qualitative research: a methodological discussion. Journal of the American Society for Information Science and Technology, 57, 1284-1295.

Meisel, S. F., Drury, H., \& Perera-Delcourt, R. P. (2018). Therapists' attitudes to offering eCBT in an inner-city IAPT service: a survey study. The Cognitive Behaviour Therapist, 11, e11. doi: 10.1017/S1754470X18000107

Mental Health UK (2021). What is anxiety? Retrieved from: https://mentalhealth-uk.org/help-and-information/conditions/ anxiety-disorders/what-is-anxiety/

Mitchell, N. (2009). Computerised CBT self-help for depression in higher education: reflections on a pilot. Counselling \& Psychotherapy Research, 9, 280-286. doi: 10.1080/14733140902993343

Mitchell, N., \& Dunn, K. (2007). Pragmatic evaluation of the viability of CCBT self-help for depression in higher education. Counselling \& Psychotherapy Research, 7, 144-150. doi: 10.1080/14733140701565987

Mitchell, N., \& Gordon, P. K. (2007). Attitudes towards computerized CBT for depression amongst a student population. Behavioural and Cognitive Psychotherapy, 35, 421-430. doi: 10.1017/S1352465807003700

Morkis, S. (2018). Patients waiting more than a year for psychological treatment in Tayside. The Courier.co.uk, 25 June 2018. Retrieved from: https:/www.thecourier.co.uk/fp/news/local/perth-kinross/675753/patients-waiting-more-than-a-year-forpsychological-treatment-in-tayside/

Morrison, L., Joseph, J., Andreou, P., \& Yardley, L. (2009) Application of the LifeGuide: A think-aloud study of users' experiences of the 'Internet Doctor'. Paper presented at the 5th International Conference on e-Social Science, Cologne, Germany.

Morse, J. M. (1995). The significance of saturation. Qualitative Health Research, 5, 147-149. doi: 10.1177/ 104973239500500201

Murray, C., \& Sixsmith, J. (2002). Qualitative health research via the internet: practical and methodological issues. Health Informatics Journal, 8, 47-53.

National Health Service Lothian (NHS Lothian) (2019). Computerised Cognitive Behavioural Therapy. Edinburgh, UK: NHS. Retrieved from: https://apps.nhslothian.scot/refhelp/MentalHealthAdult/PSYCHOLOGYBEHAVIOURALSERVICESADULT/ ComputerisedCBT

National Institute for Health and Care Excellence (NICE) (2006). Computerised cognitive behaviour therapy for depression and anxiety. Review of Technology Appraisal 51. London: NICE.

National Institute for Health and Care Excellence (NICE) (2009a). Depression in adults: the treatment and management of depression in adults. National Clinical Practice Guideline 90. London: NICE.

National Institute for Health and Care Excellence (NICE) (2009b). Depression in adults with a chronic physical health problem - treatment and management. National Clinical Practice Guideline 91. London: NICE.

National Institute for Health and Care Excellence (NICE) (2014). The global crisis of depression. London: NICE.

Nelson, C. B., Abraham, K. M., Walters, H., Pfeiffer, P. N., \& Valenstein, M. (2014). Integration of peer support and computerbased CBT for veterans with depression. Computers in Human Behavior, 31, 57-64. doi: 10.1016/j.chb.2013.10.012

Olthuis, J. V., Watt, M. C., Bailey, K., Hayden, J. A., \& Stewart, S. H. (2015). Therapist-supported internet cognitive behavioural therapy for anxiety disorders in adults. Cochrane Database Systematic Reviews (3), CD011565. doi: 10.1002/14651858.Cd011565

Păsărelu, C. R., Andersson, G., Bergman Nordgren, L., \& Dobrean, A. (2017). Internet-delivered transdiagnostic and tailored cognitive behavioral therapy for anxiety and depression: a systematic review and meta-analysis of randomized controlled trials. Cognitive Behaviour Therapy, 46, 1-28. doi: 10.1080/16506073.2016.1231219

Perera-Delcourt, R. P., \& Sharkey, G. (2019). Patient experience of supported computerized CBT in an inner-city IAPT service: a qualitative study. The Cognitive Behaviour Therapist, 12. doi: 10.1017/S1754470X18000284

Pitard, J. (2017). A journey to the centre of self: positioning the researcher in autoethnography. Forum Qualitative Social Research, 18, 20.

Proudfoot, J. (2004). Computer-based treatment for anxiety and depression: is it feasible? Is it effective? Neuroscience and Biobehavioral Reviews, 28, 353-363.

Proudfoot, J., Swain, S., Widmer, S., Watkins, E., Goldberg, D., Marks, I., . . \& Gray, J. A. (2003). The development and beta-test of a computer-therapy program for anxiety and depression: hurdles and lessons. Computers in Human Behavior, 19, 277-289. doi: 10.1016/S0747-5632(02)00062-6

Pyett, P. M. (2003). Validation of qualitative research in the 'real world'. Qualitative Health Research, 13, $1170-1179$.

Richards, D., Duffy, D., Blackburn, B., Earley, C., Enrique, A., Palacios, J., . . \& Timulak, L. (2018). Digital IAPT: the effectiveness and cost-effectiveness of internet-delivered interventions for depression and anxiety disorders in the Improving Access to Psychological Therapies programme: study protocol for a randomised control trial. BMC Psychiatry, 18, 59. doi: 10.1186/s12888-018-1639-5

Richards, D., \& Richardson, T. (2012). Computer-based psychological treatments for depression: a systematic review and meta-analysis. Clinical Psychology Reviews, 32, 329-342. doi: 10.1016/j.cpr.2012.02.004

Richards, D., Timulak, L., Doherty, G., Sharry, J., McLoughlin, O., Rashleigh, C., . . \& Joyce, C. (2014). Low-intensity internet-delivered treatment for generalized anxiety symptoms in routine care: protocol for a randomized controlled trial. Trials, 15, 145-145. doi: 10.1186/1745-6215-15-145 
Rost, T., Stein, J., Lobner, M., Kersting, A., Luck-Sikorski, C., \& Riedel-Heller, S. G. (2017). User acceptance of computerized cognitive behavioral therapy for depression: systematic review. Journal of Medical Internet Research, 19, e309. doi: 10.2196/jmir.7662

Santucci, L., McHugh, R., Elkins, R., Schechter, B., Ross, M., Landa, C., .. \& Barlow, D. (2014). Pilot implementation of computerized cognitive behavioral therapy in a university health setting. Administration and Policy in Mental Health, 41, 514-521.

Scottish Intercollegiate Guidelines Network (SIGN) (2010). Non-Pharmaceutical Management of Depression in Adults: A National Clinical Guideline, 114. N.Q.I. Scotland.

Shah, S. M. A., Mohammad, D., Qureshi, M. F. H., Abbas, M. Z., \& Aleem, S. (2021). Prevalence, psychological responses and associated correlates of depression, anxiety and stress in a global population, during the coronavirus disease (COVID-19) pandemic. Community Mental Health Journal, 57, 101-110. doi: 10.1007/s10597-020-00728-y

Smith, L., Jacob, L., Yakkundi, A., McDermott, D., Armstrong, N. C., Barnett, Y., . . \& Tully, M. A. (2020). Correlates of symptoms of anxiety and depression and mental wellbeing associated with COVID-19: a cross-sectional study of UK-based respondents. Psychiatry Research, 291, 113138. doi: 10.1016/j.psychres.2020.113138

So, M., Yamaguchi, S., Hashimoto, S., Sado, M., Furukawa, T. A., \& McCrone, P. (2013). Is computerised CBT really helpful for adult depression? - a meta-analytic re-evaluation of CCBT for adult depression in terms of clinical implementation and methodological validity. BMC Psychiatry, 13, 113. doi: 10.1186/1471-244X-13-113

SPICe (2014). SPICe Briefing Mental Health in Scotland. Retrieved from: http://www.scottish.parliament.uk/ ResearchBriefingsAndFactsheets/S4/SB_14-36.pdf

Spurgeon, J. A., \& Wright, J. H. (2010). Computer-assisted cognitive-behavioral therapy. Current Psychiatry Reports, 12, 547-552. doi: 10.1007/s11920-010-0152-4

Stefanopoulou, E., Lewis, D., Taylor, M., Broscombe, J., \& Larkin, J. (2019). Digitally delivered psychological interventions for anxiety disorders: a comprehensive review. Psychiatric Quarterly, 90, 197-215. doi: 10.1007/s11126-018-9620-5

Taiminen, H. M., Saraniemi, S., Joffe, G., Stenberg, J.-H., \& Parkinson, J. (2019). Reducing health inequalities trough digital options in mental health: a physician's perspective. Health Marketing Quarterly, 36, 93-106. doi: 10.1080/ 07359683.2019.1575059

The Scottish Government (2017). Online Support for Mental Health: Computerised CBT Rolls Out Across Scotland. Retrieved from: https://news.gov.scot/news/online-support-for-mental-health

Thew, G. (2020). IAPT and the internet: the current and future role of therapist-guided internet interventions within routine care settings. Cognitive Behaviour Therapist, 13. doi: 10.1017/S1754470X20000033

Titov, N., Andrews, G., \& Sachdev, P. (2010). Computer-delivered cognitive behavioural therapy: effective and getting ready for dissemination. F1000 Medicine Reports, 2, 49. doi: 10.3410/M2-49

Titov, N., Dear, B., Nielssen, O., Staples, L., Hadjistavropoulos, H., Nugent, M., . . \& Kaldo, V. (2018). ICBT in routine care: a descriptive analysis of successful clinics in five countries. Internet Interventions, 13, 108-115. doi: 10.1016/j.invent. 2018.07.006

Vos, T., Flaxman, A. D., Naghavi, M., Lozano, R., Michaud, C., Ezzati, M., . . \& Memish, Z. A. (2012). Years lived with disability (YLDs) for 1160 sequelae of 289 diseases and injuries 1990-2010: a systematic analysis for the Global Burden of Disease Study 2010. Lancet, 380, 2163-2196. doi: 10.1016/s0140-6736(12)61729-2

Wagner, B., Horn, A. B., \& Maercker, A. (2014). Internet-based versus face-to-face cognitive-behavioral intervention for depression: a randomized controlled non-inferiority trial. Journal of Affective Disorders, 152-154, 113-121. doi: 10. 1016/j.jad.2013.06.032

Wells, M. J., Owen, J. J., McCray, L. W., Bishop, L. B., Eells, T. D., Brown, G. K., . \& \& Wright, J. H. (2018). Computerassisted cognitive-behavior therapy for depression in primary care: systematic review and meta-analysis. Primary Care Companion CNS Disorders, 20. doi: 10.4088/PCC.17r02196

Wittchen, H. U., Jacobi, F., Rehm, J., Gustavsson, A., Svensson, M., Jonsson, B., . . \& Steinhausen, H. C. (2011). The size and burden of mental disorders and other disorders of the brain in Europe 2010. European Journal of Neuropsychopharmacology, 21, 655-679. doi: 10.1016/j.euroneuro.2011.07.018

World Health Organisation (WHO) (2012). Depression in Europe. Retrieved from: http://www.euro.who.int/en/countries/ tajikistan/news/news/2012/10/depression-in-europe

Wright, J. H., Owen, J. J., Richards, D., Eells, T. D., Richardson, T., Brown, G. K., . . \& Thase, M. E. (2019). Computerassisted cognitive-behavior therapy for depression: a systematic review and meta-analysis. Journal of Clinical Psychiatry, 80. doi: $10.4088 /$ JCP.18r12188

Cite this article: Du E, Quayle E, and Macleod H. A qualitative study of patients' experiences and acceptance of computerised cognitive behavioural therapy in primary care, Scotland. The Cognitive Behaviour Therapist. https://doi.org/10.1017/ S1754470X21000210 